\title{
Medical Conferences: value for money?
}

\author{
Michael Swash ${ }^{1}$ and Andrew Lees ${ }^{2}$
}

\author{
${ }^{1}$ Barts and the London School of Medicine, QMUL \\ and Institute of Neuroscience, University of Lisbon, Portugal \\ ${ }^{2}$ National Hospital for Neurology and Neurosurgery, University College, London
}

Correspondence: mswash@btinternet.com

Dept of Neurology, The Royal London Hospital, London E1 1BB UK

Tel/fax: +442076384043 
"It is not long since a medical congress was an event of the year, but such congresses are now so varied and numerous that they extend throughout the entire twelve months...." Editorialist $1903^{1}$

"...travel the world to the detriment of their metabolism and sleep rhythm to hear the same pieces of research described in slighty different terms by their colleagues when they might just as well have read the reports in comfort in their own living rooms." Editorialist $1960^{2}$

Does anything change? Why do we attend congresses? Such meetings are also popular in science and engineering, literature and the arts, business and finance. But it's time to consider what is gained.

\section{The modern medical congress:}

Worldwide there may be as many as 100,000 medical meetings every year. Flocks of young and not so young physicians, surgeons and others take time away from their patients and labs, and fly to faraway destinations to listen to others (often the same experts at different meetings), invited by somewhat obscure selection processes to entertain and instruct their peers and juniors. Several thousand may attend the larger congresses. Taxis, trains, airlines, hotels, restaurants, tailors and dress-makers, luggage manufacturers and professional conference organisers are kept busy. CME points are gained, much jetlag is engendered and a great deal of carbon released into the atmosphere - as much as 10,000 tons for a middlesized conference. ${ }^{3}$

It is undeniably exciting to go somewhere new, perhaps to another country, to meet one's colleagues and friends in a new environment, to make new acquaintances, and perhaps to learn something. But the reality is different: one often sits on uncomfortable, gilt-steel hotel chairs in a cold, over-air conditioned ballroom to listen to a resumé of material one has already read, or ought to have already read, the whole accompanied by a blizzard of visual aids, often presented on several enormous multi-media screens. People come and go during the presentations, chat to each other and fall asleep as their jetlag and breakfast overwhelm them. Often, one finds oneself seated behind someone holding aloft an iPad or mobile phone obstructing the sightlines of those behind them in order to photograph each and 
every slide. What do they do with the images? Many of the attendees are not listening to the speakers but texting or twittering each other, or reading their email. Others are eating or drinking, often dozing. And when it comes to question time, how curious that the same people seize the microphone again and again, perhaps attempting to be recognised as coexpert in the subject under discussion, or simply to show that, yes, they are in the audience and were not asleep. On the rostrum the speaker is so blinded by a spotlight that at first it is difficult to sense the audience at all. Adjusting to the illumination, a host of tiny red lights become evident, like fireflies, that's the mobile phone and iPad brigade. The sound system is invariably directed toward the audience, not toward the rostrum, so that for the speaker questioners' voices are distorted, barely audible, and frequently extremely difficult to localise; a particular hazard for those whose first language is not English.

Poster sessions were introduced to allow increased participation by young conference-goers , but they lack focus, and standards are variable. Too many are simply neglected by the disorientated registrants, perhaps because they are single case reports or consist of previously published material. It is not uncommon for the first author and presenter to be absent, being fully occupied chatting to friends over a glass of wine or organising the evening's entertainment. For some of these delegates the poster was the passport for attendance at the extravaganza. Some congresses have no limit to the number of posters one delegate can present. Fewer than half of the posters will appear as peer-reviewed papers in a journal of note ${ }^{4}$ surely an indictment of their quality. Conference organisers surely have a duty to separate the gold from the merely 'I was there too' offerings '? At the larger congresses mammoth, richly-furnished, company stands, usually temptingly close to the posters, offer coffee, pastries and ice cream together with 'educational material', pens and pencils, and memory sticks, in a format difficult to resist, providing welcome relief from the plethora of simultaneous academic sessions. There are so many sessions that sometimes an invited speaker may be seen addressing an almost empty hall, while the corridors and coffee stops are congested with delegates. How many congress delegates can cope with 20-30 oral papers and and several rooms of posters a day for several days? ${ }^{5}$

\section{The issues:}


In general, there are five objectives of attendance at a conference - to present one's own work in order to obtain critical comments, to learn something new, to make new acquaintances, to start collaborative research and, not least, to explore a new cultural environment. Sadly, the relevance of these objectives is questionable in the current overactive congress environment. As long ago as 1903 an Editorialist ${ }^{1}$ complained that there were too many medical conferences, often in far away destinations, that large conferences were expensive, that the abstracts did not reflect the presentations, that many papers were "of merely academic interest", that speaker discipline was poor, and that the information given could be learned more quickly by staying at home and reading the journals. That the social events offered by congresses were popular features was noted in 1903 when it was commented that tickets for social events were always in high demand ${ }^{1}$ and, in 1893 , that "next year the Norwegian doctors intend holding their congress in a yacht". ${ }^{6}$ Plus ça change, plus c'est la même chose.

Congresses aim to disseminate and advance research, to teach, to educate, to foster collaborations, to provide a forum for job opportunities, and opportunities to review evidence-based policies and guidelines.$^{7}$ They also afford major commercial opportunities for the organisers, which are often dedicated medical communication companies. However, other than self-congratulatory messages posted on websites by the organisers in the days after the congress has closed, there is little or no evidence that these aims are achieved - or indeed that they were ever realistic. What is gained from this industrial scale program of human activity? ${ }^{1}$ There are no objective analyses of the supposed benefits, either of attendance or of speaking at medical congresses. Yet it is commonly believed to be an important experience for young physicians or researchers, and also for established clinicians, to attend such meetings, and poster presentations and speaker engagements are faithfully recorded in CV's. CME points are usually garnered from such attendances in recognition of the supposed value of attendance. ${ }^{8}$ Certainly, it can be a major, unforgettable experience to hear a truly expert and international figure review his or her understanding of a difficult area of science, but such presentations are rare. As loannidis ${ }^{3}$ commented, those who dominate at large symposia are not always those of greatest scientific merit, hard work or originality of thought but represent those who have successfully navigated the required 
power circles. The suggestion that virtual attendance through the internet can substitute for real attendance has not yet been adequately tested, and surveys of conference-goers have not strongly encouraged development of this option. Small symposia and focused workshops and seminars on the other hand, can be transcendental in their effect on young and established researchers alike. ${ }^{9}$ Such symposia are at their most influential when only small numbers attend; perhaps $<40$. Genuine, informed exchange of information and ideas is then facilitated.

At the next major conference, with its 10-20,000 delegates, data on attendance at the sessions (not registration but real attendance), number of visitors to each poster, number of questions asked, the expenditure required of each delegate, including hotel, total travel and subsistence, perceived benefit, and information on arrangements for patient care in the absence of the delegate should be obtained. Some attempt to measure changed performance when back home would be of interest, although admittedly difficult to acquire. Nonetheless, an analysis of the supposed intellectual and clinical benefits should be rigorously sought. It is probably unrealistic to seek access to the organiser's financial data, but such information would be interesting. If the organiser is a learned society what use is put to the profits from the meeting for the betterment of patient care and further education of doctors?

What are the criteria for CME recognition? At present, we suggest, the conference industry seems more directed toward profit for the organiser and invited speakers than necessarily and primarily toward benefit to the attendees and their clinical and academic work. This concern should be addressed by rigorous analysis, not by opinion.

It's surely time, therefore, for a proper, in depth analysis of this huge industry - after all, we are all paying for it. 


\section{References}

1. Davis D, Thomson O'Brien MA, Freemantle N, Wolf F, Mazmanian P, Taylor-Vaisey A. Impact of formal continuing medical education: do conferences, workshops, rounds and other traditional continuing education activities change physician behavior or health outcomes? JAMA 1999;282:867-874

2. Ioannidis JP. Are medical conferences useful? And for whom? JAMA 2012;307:1257-1258

3. Editorial. Medical Congresses The Hospital 1903;34:356

4. Raloff J. Science and the public: Weighing the costs of conferencing - attemding distant meetings offers a lot of benefits, despite high costs. 2012 https://www.sciencenews.org/blog/science-public/weighing-costs-conferencing

5. FirstWord Perspectives. A hybrid model for better multichannel scientific engagement. VEEVA systems. December 2016 (accessed September 2018)

6. Blanchard RD, Engle DL, Howley LD, Whicker SA, Nagler A. From the Coliseum t the convention centre: a reflection on the current state of medical education conferences and conference-goers. Med Educ 2016;50:1258-1261

7. Elliott CA, Mehta V, Poon C, Oliver M, Gourishankar S. The fate of abstracts presented at the annual meeting of the Congress of Neurologic Surgeons. Open J Mod Neurosurg 2016;6:1-8

8. Miscellaneous Notes. Indian Med Gazette 1893;28:399

9. Editorial Comment. Conferences: big or small? Canad Med Acad J 1960;82:837 